\title{
Local area greywater symbiosis approach to a more sustainable urban water management
}

\author{
S. M. Zadeh, D. R. Lombardi, D. V. L. Hunt \& C. D. F. Rogers \\ School of Civil Engineering, University of Birmingham, UK
}

\begin{abstract}
Stress on water resources in some areas is reaching critical levels due to population growth, rapid urbanization, economic development, climate change, and an ageing infrastructure. Greywater reuse has been explored as a more sustainable water resource management option to displace demand for fresh water, largely for residential use on a household or building level. However, the infrastructure needed and the disinfectant required for greywater systems make it difficult to see these systems as environmentally friendly and cost-effective, especially for individual households. The research reported herein tests the hypothesis that greywater reuse shared amongst users in neighbouring residential, office and commercial buildings may improve the feasibility of, and hence make more sustainable, greywater recycling as part of urban water management. The local area symbiosis scheme is designed in three stages: first, calculating a balance between greywater supply and demand in the area based on class of use (residential, office, or other); second, estimate sharing (local recycling) potentials based on the quantities available and requirements for use; and finally, estimating the sustainability of the proposed system by considering the technologies and infrastructure required for implementation.
\end{abstract}

Keywords: greywater recycling, urban regeneration, reuse, sustainable urban water management, urban recycling.

\section{Today's water situation}

Almost all of the world's water (97\%) occurs as salt water. Of the remaining 3\%, two-thirds occurs as snow on ice in the polar and Alpine regions; only about $1 \%$ of global water occurs as fresh water. More than $98 \%$ of this fresh water occurs as groundwater, while less than $2 \%$ is available in streams and lakes. Liquid 
fresh water is thus a finite and limited resource [1], and is often not ideally located to supply the demand. Stress on fresh water resources in some areas is reaching critical levels due to population growth, economic development, climate change, and an ageing infrastructure. The current rapid pace of urbanization further highlights the need for an integrated and more sustainable urban water management strategy [2]. Sustainable strategies can be used to address supply and demand in urban regions. One may increase supply by developing additional local sources, such as deep sources (i.e. groundwater abstraction) and rainwater harvesting, importing water from greater distances, introducing seawater desalination, or via the construction of new dams and reservoirs. However, even where these new sources of water are technically feasible, their use may prove unsustainable due to their high direct costs for construction, operation and maintenance, and potentially negative effects on the environment [3]. The second strategy is to reduce the demand for urban water, an important contributor to improving the "sustainability performance" of the urban water system. One demand-reduction strategy is to treat urban wastewater to a sufficient quality so that it could be put to beneficial use, rather than discharge it into sewers or, where appropriate, directly into the environment [4]. Greywater is defined as the urban wastewater that includes water from baths, showers, hand basins, and washing machines, and surface drainage water, but excludes streams from toilets and kitchen sinks [5-7]. Greywater recycling and reuse can thus contribute to urban sustainability by reducing fresh water demand [8].

\subsection{Greywater recycling and reuse}

The main high-level objectives of sustainable urban water and wastewater systems include: conserving natural resources, improving health and hygiene, saving financial resources, and moving towards a non-toxic environment [9]. Greywater reuse has a significant impact on demand for fresh water supply (conserving natural resources), as well as reducing the load placed on wastewater treatment facilities (helping to move towards a non-toxic environment). However, it should be mentioned that not all of the effects brought about by greywater reuse are beneficial; for example, reusing greywater may reduce flows in sewers, resulting in a higher frequency of clogging events in existing sewers [3]. Reuse of greywater may also reduce the fresh water flows through the distribution network, leading to reduced delivery pressures and increased dwell time in pipes - both associated with lower quality fresh water delivered.

In addition, the construction of greywater systems requires the use of natural resources (for storage tanks and pipes) that will contain embodied energy. During their operation, these systems consume other resources including electricity for pumping and chemicals for disinfection. In the small-scale systems proposed for single buildings or households, such resource usage during the operation of a greywater system is proportionately far higher than that required for mains water supply.

The small financial benefits and long payback periods further compromise the sustainability credentials of greywater systems [3]. Indeed the infrastructure needed and the disinfectant required for greywater systems make it difficult to 
see these systems as environmentally friendly and cost-effective, especially for individual households. A superficial conclusion might therefore be that the natural and financial resources required for construction and operation of individual greywater systems make it less sustainable when compared to the mains water supply $[8,10]$.

\subsubsection{Greywater calculation for residential buildings}

The literature shows that the typical volume of greywater generated in residential buildings depends on living standards, population structures (age, gender), lifestyle, customs and habits, water installations and the degree of water abundance [11]. The average amount of indoor domestic water demand in the UK is 150 litres/day, comprising $50 \%$ of the total urban water demand in this country [12]. In the UK, a greywater production of up to 89 litres/person/day of the total water consumption in households may be taken as the basis for calculation for new buildings where sanitary equipment has been refurbished, and water used for toilet flushing represents $19 \%$ of the total household water usage. Greywater from baths, showers, hand basins and washing machines corresponds to $59 \%$ of total household water consumption (Figure 1).

As this analysis for residential buildings shows, the volume of water that will be available as greywater supply (59\%) is much higher than the potential for utilising the treated greywater demand for toilet flushing (19\%). In this case the amount of potable water that might be saved through greywater reuse will be relatively small, thus supporting the conclusion that it is likely not to prove beneficial in terms of overall 'sustainability performance' to use materials and other resources to construct and operate a greywater system in residential buildings.

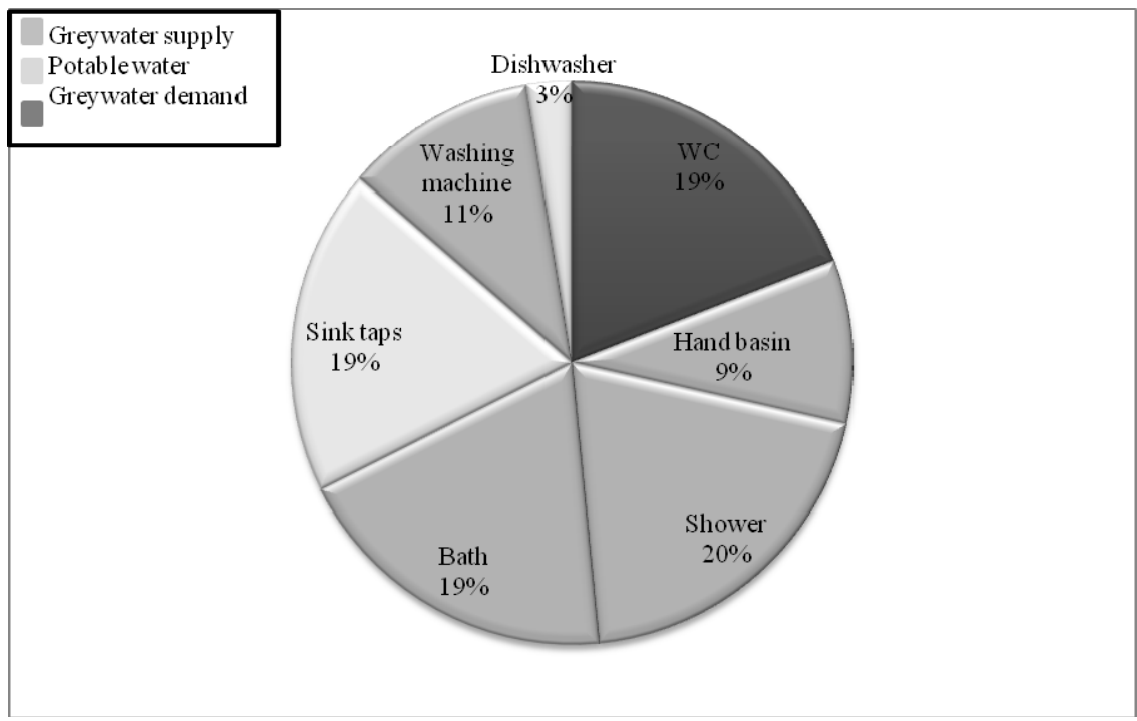

Figure 1: $\quad$ Water demand in residential buildings in the UK [13]. 


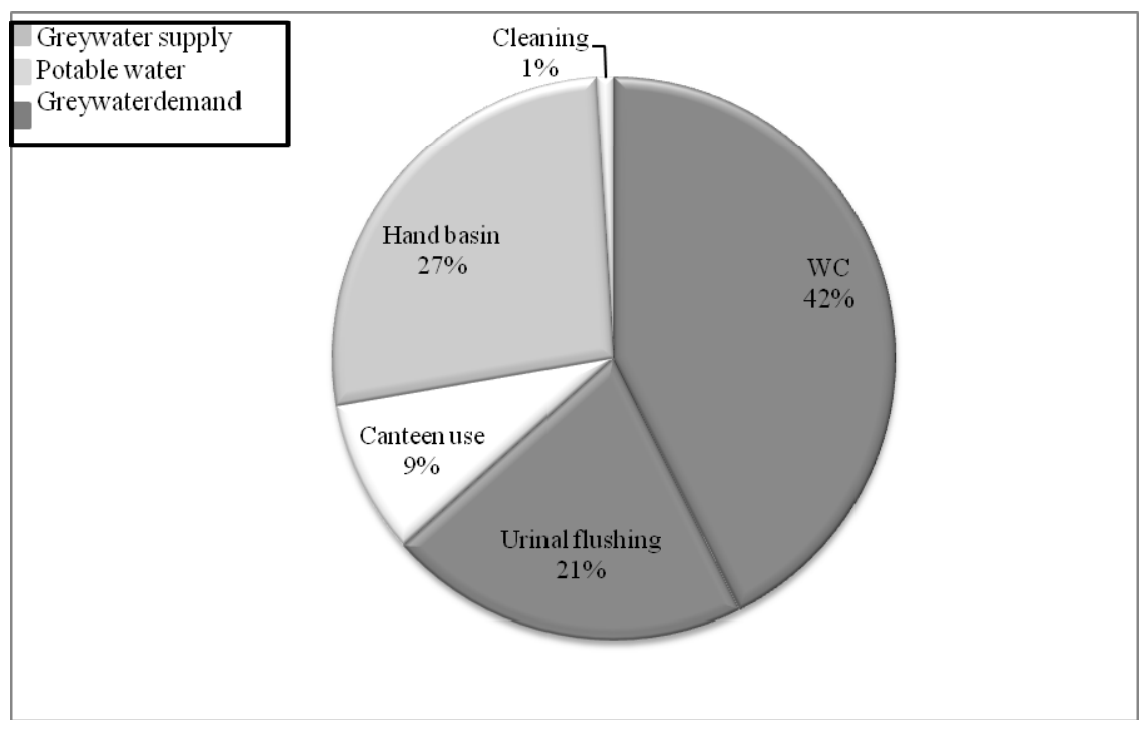

Figure 2: $\quad$ Water demand in office buildings in the UK [8].

\subsubsection{Greywater calculation for office buildings}

The water use in offices depends on several primary factors including: occupancy, size of office, age of property, type of fittings installed, maintenance and management behaviour, and user behaviour [14]. Water consumption in offices has been correlated with both the number of employees and the floor area for purposes of estimation; the study by the UK Construction Industry Research and Information Association (CIRIA) on water key performance and indicators for offices indicates that employee number is a better predictor. Therefore, the water use per employee for the best practice office used in this analysis is 7.9 litres/day, based on the recommended benchmarks by CIRIA [14]. In this study the average number taken as the occupancy in offices were assumed based on the British Council for Offices Guide [15] of $15 \mathrm{~m}^{2}$ per person.

Figure 2 presents the average distribution of water consumption in a UK office. This shows that 63\% (5.0 litres/employee/day) of office water usage is for toilet flushing, which can be replaced by treated greywater. On the other hand, the volume of greywater produced in a typical office relates to $27 \%$ (or 2.1 litres/employee/day) of office water usage for hand washing throughout the day.

The greywater produced in offices (from hand basins) is consequently substantially less than the demand for toilet flushing. Based on the water balance for UK offices, therefore, one may conclude that the limited uptake of greywater systems in offices is due to this mismatch in greywater supply (that generated) and greywater demand (uses suitable for greywater). As always, judgements have to be made on the site specifics of the building in question; if the office building in question has showers, for example, then an additional, albeit 
probably small, supply of greywater would be available. Other sources of water, such as groundwater or green water (i.e. harvested rainwater) could make up the required flushing volumes, or the shortfall could be made up by using fresh water for toilet flushing. Nevertheless, a similar conclusion might be reached to that for residential buildings, i.e. that greywater systems for offices are likely to prove inefficient, and thus ineffective, and hence do not materially contribute to making the urban water system more sustainable unless over-riding local conditions apply (such as severe local water shortages). In parts of the UK where water is relatively plentiful, an office building greywater recycling system would have little value.

\section{A greywater system based on local area symbiosis principles}

Analysis in the previous section has shown that, for the average resident, greywater production exceeds demand thus creating a surplus of greywater after meeting that resident's demand. However, individual dwelling greywater systems are expensive compared to the price of fresh water in most countries (and certainly in the UK), and the material, energy and other resources required to create and operate them are proportionately far higher than those required for a central mains water system. For the typical office, the converse is true: greywater demand exceeds that produced, thus creating a deficit of greywater; the uptake of greywater systems in offices is low due to both the small percentage of freshwater displaced and the unfavourable economic cost-benefit analysis of the system. It should be remembered that economy is one of the three pillars of sustainability and a 'sustainability solution' that is very far from being cost effective would have to deliver very great social and environmental benefits to be worthwhile.

This research is predicated on the hypothesis that the demand for potable water in a mixed-use urban area can be reduced by sharing greywater from residential users to office buildings, yielding a system of local area symbiosis for water (Figure 3). Such a system might make greywater recycling a more viable (economically, environmentally and socially) contributor to the sustainability of an integrated urban water system.

As discussed earlier for the UK, the greywater production for residential users is on average approximately 90 litres/person/day for a household, while the greywater demand in offices for use in toilet flushing is 5 litres/employee/day. Based on this information, it is possible to establish a 'rule of thumb' that each "average" UK water user in residential buildings can supply the toilet flushing demand for 18 employees in office buildings with the average UK water demand of 7.9 litres/day. This ratio allows application of this methodology generally in the UK, but can simply be adjusted for local conditions (installation of low-water usage fittings, for example). The same methodology can be extended to different use classes of building, including hotels, educational facilities, commercial malls, and so on. By extension, with country-specific usage patterns, the methodology should be applicable quite generally. 


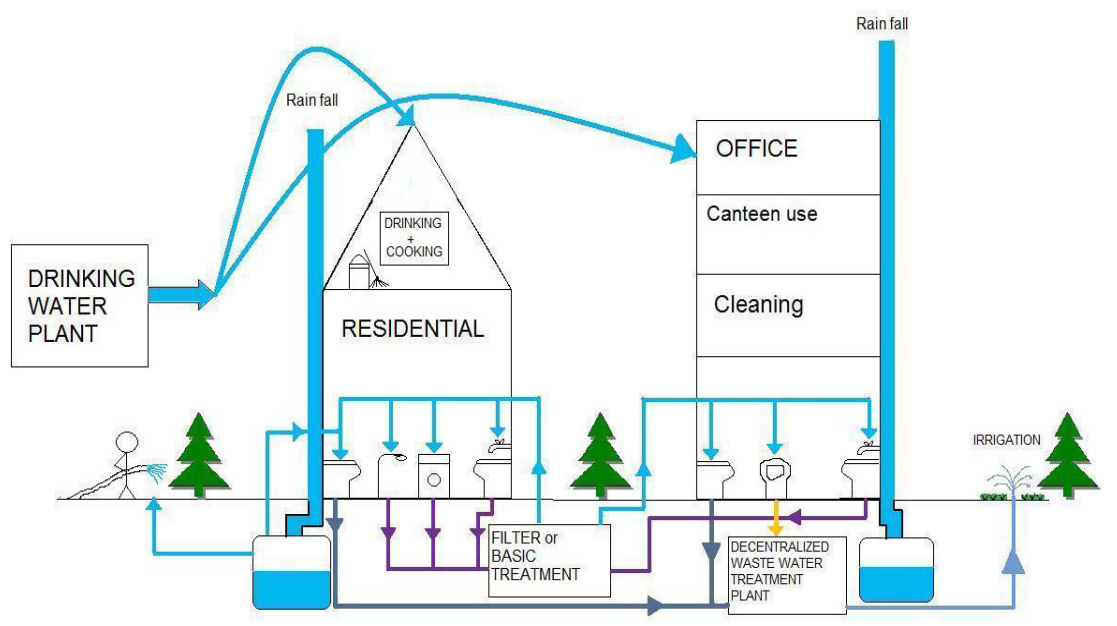

Figure 3: Principle of sharing greywater between residential and office buildings.

Table 1: $\quad$ Overall development by use in Eastside [15].

\begin{tabular}{|c|c|}
\hline Commercial & 2.8 Million Sq Ft \\
\hline Education & 1.1 Million Sq Ft \\
\hline Retail & 1 Million Sq Ft \\
\hline Leisure & 0.7 Million Sq Ft \\
\hline Residential & 4800 Apartments \\
\hline Hotel & 800 Beds \\
\hline Public Space & 8 Acres \\
\hline Car parking & 3500 Public Spaces \\
\hline
\end{tabular}

\section{Case study: Masshouse}

This section describes briefly the case study that has been chosen for this project. Birmingham Eastside is one of the largest mixed-use urban regeneration projects in UK, covering 170 hectares immediately to the east of the centre of Birmingham, one of the four major urban areas of the West Midlands in the UK. Birmingham Eastside has been described by Birmingham City Council as having the potential to be an exemplar of sustainable development, and this aspiration has informed planning documents and planning decisions. The mixed-use development in Eastside combines residential, commercial, industrial, office, institutional and other land uses (see Table 1).

A single site has been chosen in Eastside to apply the methodology: Masshouse is a 1.1 million sq $\mathrm{ft}$ mixed use development, which includes 500,000 sq ft Grade A office and two residential apartment buildings containing 340 units 
(10\% studio apartments, $60 \%$ one-bedroom apartment and 30\% two-bedroom apartments). Data collection for these buildings has been undertaken through telephone and email contact with relevant members of the developer's teams, as well as planning applications and marketing materials.

\subsection{Water balance calculation}

The initial and straightforward step is to calculate the water balance for the two residential and one office building in the Masshouse development to estimate the volume of potential greywater generation in the residential buildings and the potential greywater requirement for the office building. The Masshouse residential buildings have 340 apartments; include 34 studio apartments, 204 one-bedroom apartment, and 102 two-bedroom apartments. The average occupancy per household in the UK is 2.4 people per apartment [17]. Based on this general figure, the number of occupants in Masshouse is 816 people (although a more accurate figure could be estimated on the basis of the demographic profile of the occupants in new high-quality residential units close to the city centre, or a door-to-door survey). The overall water usage of the Masshouse residential buildings is thus estimated as 122,400 litres/day, found by multiplying the 150 litres/day (average domestic water consumption) by 816 (number of occupants). The total volume of greywater production for these apartment buildings is thus 72,216 litres/day and the toilet flushing demand for these users is 23,256 litres/day using the percentages given in Figure 1.

The Masshouse office building has an area of approximately 46,000 square metres. By applying the British Council for Offices Guide [18] of $15 \mathrm{~m}^{2}$ per person, the estimated number of employees would be 3067, and given the average water consumption of 7.9 litres/employee/day in office buildings, the total water demand for Masshouse office is 24,229 litres/day. As shown in Figure 2, $63 \%$ of this office water consumption relates to toilet flushing demand, which equates to 15,264 litres/day. Once again, a refining adjustment to these figures could be made on the basis of the nature of the office building and its likely occupancy.

Combining these calculations, the amount of greywater generated in the Masshouse residential buildings can cover the whole toilet flushing demand in the Masshouse office building as well as the toilet flushing demand in the two residential buildings, and thereby potentially reduce the freshwater consumption of the Masshouse development by $26 \%$ with greywater to spare for other local area needs such as landscaping. The economic impact using today's, or projected future, economic costs can then be calculated in a straightforward manner, and these values can be adjusted for future climate trends, existing and future infrastructure costs, and 'three-pillar' costs more generally using one of the various sustainability assessment frameworks that have been developed.

\subsection{Greywater technology - further consideration}

Greywater requires processing before reuse to address high concentrations of chemicals or compounds (i.e. to meet water quality requirements relating to 
organic matter, biological oxygen demand or BOD, bacteria such as E. coli, and so on). A wide variety of technologies have been used or are being developed for greywater treatment and reuse, including natural treatment systems (e.g. construction wetlands), basic coarse filtration, chemical processes (e.g. ion exchange), physical and physiochemical processes, and biological processes (e.g. Membrane Bio Reactor, MBR) [18].

There is a lack of appropriate water quality standards or guidelines for greywater reuse in UK, which makes the sensible adoption of recycling more limited [19]. The problem is to choose a suitable technology to produce a robust effluent quality. Selection of the most appropriate technology is dependent on many factors, though especially the scale of operation, end use of the water, socioeconomic factors relating to cost of water and regional customs and practices [18]. The scale of this proposal operates at the area level, naturally limiting the selection of existing technologies.

Two potentially appropriate technical solutions for a site of this scale such as the Masshouse site are MBR and construction wetlands. Generally, the main barrier for implementing the construction wetlands option is the requirement for a relatively large land area, which is generally a significant issue in urban areas and has a large effect on the cost of system. For example the land area that is required to build the wetland for treating the greywater deriving from the Masshouse site is $1795 \mathrm{~m}^{2}$, based on $2.2 \mathrm{~m}^{2}$ area per person [20] (for the 816 estimated residents of Masshouse only - an adjustment would be required for the employees). For Birmingham Eastside, however, the option theoretically exists to incorporate such wetlands into the Eastside City Park, a 32,000 $\mathrm{m}^{2}$ urban park planned adjacent to the Masshouse site. A further extension of this research would be to assess how to safely and aesthetically design a constructed wetlands in the City Park, and further to assess the potential extension of the wetlands service to additional neighbouring buildings in Eastside such as Millennium Point, a multipurpose facility that includes educational, office and leisure facilities. Such an integrated, low energy and low resource solution appeals to a variety of sustainability criteria; its potential habitat for local biodiversity could also be considered as a benefit in this case.

The problem for MBR technologies relate to their high energy demand and consequently high operating cost. However, the membrane bioreactor technology is likely to remain as an appropriate technology for greywater recycling, particularly in collective residential buildings, due to the fact that it produces a high quality effluent and is operationally reliable [19]. Future work will examine the scalability of this technology, and its use in urban retrofitting and regeneration areas.

\section{Discussion}

The proposed local area greywater symbiosis system may prove a feasible strategy to improve the sustainability of water use in urban areas. Because of the economies of scale, it is likely to prove more cost effective compared to individual greywater systems. This contention is generally supported by the 
economic feasibility study by Friedler and Hodari [3] on greywater reuse systems in urban sectors, which shows that greywater systems become more economically feasible only when a certain building size was exceeded, this building size being dependent on local conditions. A further study by Memon et al. [2] shows that for large-scale greywater reuse systems, the whole life costing decreases and the energy consumption is also relatively low.

Risks to human health and the environment have been considered as barriers to implementing greywater recycling systems. In order to reduce these risks there is a need to manage the health risks by educating householders to ensure appropriate use of recycled water and educate plumbers on installation and maintenance matters. In the case of a large-scale system a lot of time and effort is thus required to educate the householders to reduce the risk, a task made all the harder by the findings of Jeffrey et al. [6] whose surveys show that the public perception for using recycled water in their houses is very low. With regard to this and similar studies about the adverse public perception for implementing individual greywater systems, it might be expected that greywater reuse has fewer problems with public perception were it restricted to a limited use for toilet flushing in non-residential buildings.

\section{Conclusions}

Rapid urbanization, population growth, and changes in the global economy and social behaviour of people all exert pressure on fresh water resources. Work by the UN has shown that "in an industrialised city with plenty of water, flushing the toilet in an average household can send up to 50 litres of water down the drain every day. Yet more than one in six people worldwide -1.1 billion - don't have access to 20-50 litres of safe freshwater daily, the minimum range suggested by the UN to ensure each person's basic needs for drinking, cooking and cleaning" [21]. "Sustainability" in relation to water supply is necessary to meets the needs of the present without compromising the ability of future generations to meet their own needs. Greywater use can contribute to a more sustainable use of water resources by reducing water demand through recycling and reuse of greywater. Although the use of treated greywater can reduce the volume required from the mains supply, the uptake of this system is currently very low because of the high cost of construction, operation and maintenance and the payback period for the system is greater than its lifetime.

This paper presents an alternative hypothesis that collecting greywater from net greywater producers (e.g. domestic users) and using it for toilet flushing in office or commercial buildings (where there is a net greywater demand) will improve the efficiency of this system and in turn reduce the potable water demand in mixed-use areas. The authors believe that this system improves the "sustainability credentials" of an urban water management portfolio by reducing potable water demand, and potentially decreasing the cost of the system compare to individual greywater systems and suffering less with respect to adverse public perceptions. The impacts on the current freshwater and wastewater networks must be taken into account in a fuller analysis of this potential. 
The general ratio for this hypothesis is that the amount of greywater that each person in residential buildings produces can supply the demand for greywater for 18 toilet flush users in office buildings. This can reduce the demand for potable water by up to $26 \%$, with the potential for more, based on standard UK guideline figures.

Further work for this project includes the assessment of the energy consumption for construction, operation and maintenance of such a system and its comparison with the energy consumption in individual greywater systems, as well as determining the optimal scales and mix of users for different local conditions.

\section{Acknowledgements}

The authors would like to thank the Urban Futures research team, the Sustainable Eastside research team, and the University of Exeter Centre for Water Systems for their support and for providing the required information for analysis.

\section{References}

[1] Bouwer, H., Integrated water management: emerging issues and challenges. Agriculture Water Management, 45, pp. 217 228, 2000.

[2] Memon, F.A., Zheng, A., Butler, D., Shirley-Smith, C., Life cycle Impact Assessment of greywater recycling technologies for new developments. Environ Monitoring Assess, 129, pp. 27_35, 2007.

[3] Friedler, E., Hadari, M., Economic feasibility of on-site greywater reuse in multi-story buildings. Desalination, 190,pp. 221_234, 2006.

[4] Li, F., Wichmann, K., Otterpohl, R., Evaluation of appropriate technologies for greywater treatments and reuses. Water Science and Technology, 59(2), pp. 249_260, 2009.

[5] Erikson, E., Auffarth, K., Henze, M., Ledin, A., Characteristics of grey wastewater. Urban Water, 4(1), pp. 85_104, 2002

[6] Jeffery, P., Jefferson, B., Public receptivity regarding in-house water recycling: Results from a UK survey. Water Science and Technology: Water Supply, 3(3), pp. 109_116, 2003.

[7] Otterpohl, R., Albold, A., Olgenburg, M., Sources control in urban sanitation and waste management: Ten systems with reuse of resources. Water Science and Technology, 39(5), pp. 153_160, 1999.

[8] Leggett, D.J., Shaffer, P., Building that save water - rainwater and greywater use. Proceedings of the Institution of Civil Engineers, Municipal Engineer, 151(3), pp. 189_196, 2002.

[9] Hellestorm, D., Karrman, E., A framework for systems analysis of sustainable urban water management. Environmental Impact Assessment Review, 20, pp. 311_321, 2000.

[10] Memon, F.A., Butler, D., Economic assessment tool for greywater recycling systems. Proceedings of the Institution of Civil Engineers. Engineering Sustainability, ES3, pp. 155_161, 2005. 
[11] Morel, A., Diener, S., Grey water management in low and middle-income countries. Water and Sanitation in Developing Countries. Eawag, Swiss Federal Institute of Aquatic Science and Technology, 2006. Accessed in 2009 at www.sandec.ch

[12] Future Water. The Government's Water Strategy for England. February 2008, DEFRA (Department for Environment Food and Rural Affairs). Access on 2010 at http://www.defra.gov.uk/environment/quality/water/ strategy/pdf/future-water.pdf

[13] Environment Agency. Water resources for the future. A summary of the strategy for England and Wales, Environment Agency, 2001.

[14] Waggett, R., Arotsky, C., Water key performance indicators and benchmarks for offices and hotels (CIRIA - C657), pp.56, 2006.

[15] British Council for Offices. Access on 2010 at .http://www.bco.org.uk/

[16] Eastside development, access in 2009 at http://www.eastsidebirmingham.co.uk/

[17] Yao, R., Steemers, K., A method of formulating energy load profile for domestic buildings in the UK. Energy and Buildings, 37(6), pp. 663_671, 2004.

[18] Jefferson, B., Palmer, A., Jeffery, P. Stuetz, R. Judd, S., Greywater characterisation and its impact on the selection and operation of technologies for urban reuse. Water Science and Technology, 50(2), pp. 157 164, 2004.

[19] Lazarova, V., Hills, S., Birks, R., Using recycled water for non-potable, urban uses, a review with particular reference to toilet flushing. Water Science and Technology, 3(4), pp. 69-77, 2003.

[20] Brix, H., Vymazal, J., Brix, H., Cooper, P.F., Green, M.B., Haberl, R. (Eds.), Constructed wetlands for wastewater treatment in Europe. Backhuys Publishers, Leiden, The Netherlands, page 123-152, 1998.

[21] UN Water. 2007 World Water Day - Every Drop Counts. Accessed March 2010. http://www.fao.org/nr/water/docs/wwd07brochure.pdf 